\title{
Malignant Peritoneal and Retroperitoneal Neoplasm
}

National Cancer Institute

\section{Source}

National Cancer Institute. Malignant Peritoneal and Retroperitoneal Neoplasm. NCI

Thesaurus. Code C156711.

A primary or metastatic malignant neoplasm that affects the peritoneum and/or retroperitoneum. 